\title{
On the role of intervening distractors in the attentional blink
}

\author{
Benoit Brisson - Thomas M. Spalek • Vincent Di Lollo
}

Published online: 9 November 2010

(C) Psychonomic Society, Inc. 2010

\begin{abstract}
The attentional blink (AB) refers to the decline in accurate report for a second target (T2) when presented within about $500 \mathrm{~ms}$ of a first target (T1) embedded in a rapid serial visual presentation stream of distractors. It is debated whether the distractors presented shortly after $\mathrm{T} 1$ cause the AB directly, as is proposed by distractor-based models, or can modulate its amplitude only indirectly by increasing $\mathrm{T} 1$ difficulty, as is proposed by capacity-based models. To investigate this issue, an intervening distractor was presented at lag $1(\mathrm{~T} 1+1)$, at lag $2(\mathrm{~T} 1+2)$, or at neither of these two lags (no distractor). $\mathrm{T} 2$ was presented at either lag 3 or 9. An AB was observed even in the absence of intervening distractors, indicating that distractors are not necessary to produce an $\mathrm{AB}$. Nonetheless, the $\mathrm{T} 1+2$ distractor did modulate the $\mathrm{AB}$ directly, without influencing T1 performance. Neither theory can fully account for the results but can do so given some modifications.
\end{abstract}

Keywords Dual-task interference - Attentional blink . Short-term consolidation - Attentional selection · Distractor interference - Attentional filter. Task switching

The attentional blink (AB; Raymond, Shapiro, \& Arnell, 1992) refers to a decline in accurate reporting of a second target (T2) when it is presented within about half a second of a first target (T1) in a rapid serial visual presentation (RSVP) of distractors. The AB has been the topic of extensive research in the past couple of decades, and its

B. Brisson · T. M. Spalek • V. Di Lollo

Department of psychology, Simon Fraser University,

Burnaby, British Columbia, Canada

B. Brisson $(\square)$

Département de psychologie, C.P. 500,

Université du Québec à Trois-Rivières,

Trois-Rivières, Québec G9A 5H7, Canada

e-mail: Benoit.Brisson@uqtr.ca popularity is ever-growing. Its appeal is in part linked to the belief that it reflects a severe and fundamental limitation in human cognitive abilities.

The $\mathrm{AB}$ is a remarkably robust phenomenon, but its underlying causes are a source of debate. One class of theories points to capacity limitations as the root cause of the $\mathrm{AB}$; other theories implicate the distractors that intervene between $\mathrm{T} 1$ and T2. In the present study, we sought to distinguish between these two views by systematically investigating the role of intervening distractors in the $\mathrm{AB}$.

Early theories of the $\mathrm{AB}$, such as the two-stage model (Chun \& Potter, 1995) and the central interference theory (Jolicoeur, 1998), proposed that when attentional mechanisms are engaged in consolidating $\mathrm{T} 1$, they are not available for consolidating T2 into visual short-term memory (VSTM). As a consequence, consolidation of $\mathrm{T} 2$ is subject to a delay, during which the $\mathrm{T} 2$ representation decays and is vulnerable to overwriting by trailing items. These capacity-based theories are bolstered by the finding that the magnitude of the $A B$ is related directly to the difficulty of $\mathrm{T} 1$ processing. For example, inserting a blank frame after T1 (i.e., removing the T1 mask) leads both to improved $\mathrm{T} 1$ identification and to a reduced $\mathrm{AB}$ (Chun \& Potter, 1995; Raymond et al., 1992). The reduction in $\mathrm{AB}$ is explained as follows. Removal of the trailing mask allows faster processing of $\mathrm{T} 1$, with a corresponding reduction in the delay of $\mathrm{T} 2$ processing. The shorter delay permits $\mathrm{T} 2$ to be consolidated sooner, thus reducing the probability of decay and overwriting by trailing items.

Capacity-based theories have been challenged by recent findings; when three successive targets (T1, T2, T3) are inserted in an RSVP stream of distractors, no $\mathrm{AB}$ is in evidence for either $\mathrm{T} 2$ or $\mathrm{T} 3$. In contrast, when $\mathrm{T} 2$ is replaced by a distractor, $\mathrm{T} 3$ exhibits a substantial $\mathrm{AB}$ (Di Lollo, Kawahara, Ghorashi, \& Enns, 2005; Olivers \& Meeter, 2008; Olivers, van der Stigchel, \& Hulleman, 
2007). What capacity-based theories cannot explain is why an $A B$ is not found when the system's resources are taxed with three targets but crops up when processing demands are reduced by omitting one of the targets.

The absence of an $\mathrm{AB}$ with multiple successive targets has prompted a new set of accounts, known collectively as input-control theories. These accounts maintain that the $\mathrm{AB}$ is triggered not by $\mathrm{T} 1$, but by the distractor directly following T1. Two original input-control models have been proposed: the temporary loss of control (TLC) model (Di Lollo et al., 2005) and the boost and bounce (BB) model (Olivers \& Meeter, 2008; Olivers et al., 2007).

According to the TLC model (Di Lollo et al., 2005), target selection is mediated by an input filter set to pass targets and reject distractors. The filter is actively maintained by signals from a central executive, which is also required for consolidating targets into VSTM. A key assumption is that the central executive cannot keep on issuing maintenance signals while consolidating an item into VSTM. As a consequence, while $\mathrm{T} 1$ is being consolidated, the filter becomes vulnerable to disruption. If the item following $\mathrm{T} 1$ is another target, the filter's configuration remains unchanged. If, however, the item following $\mathrm{T} 1$ is a distractor, the filter's configuration is disrupted. The $\mathrm{AB}$ occurs when $\mathrm{T} 2$ is presented after the filter has been disrupted but before there has been sufficient time to reconfigure it once $\mathrm{T} 1$ has been processed.

The BB model of Olivers et al. (2007; Olivers \& Meeter, 2008), on the other hand, proposes that the post-T1 distractor is enhanced by the excitatory attentional response evoked by $\mathrm{T} 1$. This, in turn, triggers a strong inhibitory response, which affects subsequent targets. In brief, both the TLC and the $\mathrm{BB}$ models claim that the $\mathrm{AB}$ occurs because the post-T1 distractor triggers critical changes in input control, causing ensuing targets to be missed until normal control is restored.

As is clear from the foregoing, assessing the role of intervening distractors in the $\mathrm{AB}$ has important theoretical implications. The goal of the present study was to determine whether distractors cause the $\mathrm{AB}$ directly, as is proposed in distractor-based models, or can modulate the $\mathrm{AB}$ only indirectly by modulating $\mathrm{T} 1$ processing, as is proposed in capacity-based models

To achieve this goal, our principal manipulation was whether or not a distractor was presented in one of the two RSVP frames following T1 (i.e., at lag 1 or at lag 2). A distractor could be presented at lag $1(100 \mathrm{~ms}$ after $\mathrm{T} 1$ onset; the $\mathrm{T} 1+1$ condition), at lag $2(200 \mathrm{~ms}$ after $\mathrm{T} 1$ onset; the $\mathrm{T} 1+2$ condition), or at neither lag (no-distractor condition). The intertarget lag was either short (lag 3; in which case, $\mathrm{T} 2$ was presented during the period of the $\mathrm{AB}$ ) or long (lag 9; in which case, T2 was presented beyond the period of the $\mathrm{AB}$ ). The display sequence for each of the three conditions is illustrated in Fig. 1 for the short intertarget lag.

\section{Theoretical considerations}

Predictions from the distractor-based and the capacitybased models are outlined below. In the present work, the magnitude of the $\mathrm{AB}$ was estimated by subtracting the percentage of correct $\mathrm{T} 2 \mid \mathrm{T} 1$ responses at lag 3 (at which $\mathrm{T} 2$ was presented during the period of the $\mathrm{AB}$ ) from the corresponding score at lag 9 (at which $\mathrm{T} 2$ was presented beyond the period of the $\mathrm{AB}$ ).

No-Distractor condition Distractor-based theories predict that no $\mathrm{AB}$ should occur in this condition simply because there are no intervening distractors to disrupt input control. Predictions from capacity-based models depend on whether the processing of $\mathrm{T} 1$ has been completed during the $300-\mathrm{ms}$ period between the onset of $\mathrm{T} 1$ and the onset of $\mathrm{T} 2$. In conventional studies, the distractor presented directly after $\mathrm{T} 1$ acts as a mask that slows the processing of T1. This delays the consolidation of $\mathrm{T} 2$, thereby extending the period of the AB. The absence of a mask in the nodistractor condition should permit faster processing of $\mathrm{T} 1$ with correspondingly smaller $\mathrm{AB}$ than in the $\mathrm{T} 1+1$ condition.

$T 1+1$ condition Both theories predict that an $\mathrm{AB}$ should occur in the $\mathrm{T} 1+1$ condition and that it should be larger than in the no-distractor condition. According to distractorbased theories, the $\mathrm{AB}$ should occur because input control is disrupted by the distractor presented directly after T1. According to capacity-based theories, the AB should occur because the processing of $\mathrm{T} 1$ is delayed by the mask in the $\mathrm{T} 1+1$ condition, but not in the no-distractor condition.

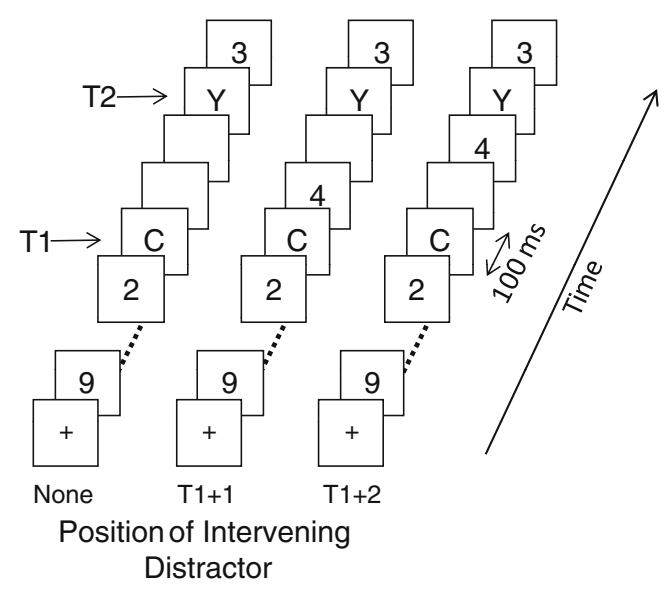

Fig. 1 Schematic representation of the short intertarget lag display sequence in Experiment 1. T1, first target; T2, second target 
$T 1+2$ condition Distractor-based theories predict that the distractor presented immediately before $\mathrm{T} 2$ will cause a disruption in input control and, hence, an $\mathrm{AB}$ at least as large as that in the $\mathrm{T} 1+1$ condition. This is because, in the $\mathrm{T} 1+1$ condition, there is a 100 -ms blank during which input control could conceivably begin to be restored. In contrast, no such period is available in the $\mathrm{T} 1+2$ condition, in which $\mathrm{T} 2$ is presented directly after the disruptive distractor. According to capacity-based theories, the distractor in the $\mathrm{T} 1+2$ condition is presented too late to be an effective mask for T1 (Enns, 2004). Given negligible masking of $\mathrm{T} 1$, the $\mathrm{T} 1+2$ condition becomes functionally equivalent to the no-distractor condition, thus yielding $\mathrm{ABs}$ of comparable magnitudes.

To anticipate, in Experiment 1, where the first task was to identify whether $\mathrm{T} 1$ was $\mathrm{A}, \mathrm{B}, \mathrm{C}$, or D and the second task was to detect whether T2 was or was not $\mathrm{Y}$, we found strong evidence in favor of capacity-based models. First, an $\mathrm{AB}$ was observed even when no distractors were presented between $\mathrm{T} 1$ and $\mathrm{T} 2$. Second, an intervening distractor modulated the $\mathrm{AB}$ only if it affected $\mathrm{T} 1$ performance. But distractor-based models could also account for these results on the grounds of a task switch between $\mathrm{T} 1$ and $\mathrm{T} 2$ that might have disrupted input control. In Experiment 2, we removed the task switch and still observed an $\mathrm{AB}$ in the nodistractor condition, confirming that the presence of intervening distractors is not necessary to produce the $\mathrm{AB}$. However, Experiment 2 also produced evidence consistent with distractor-based accounts. To wit, we found that the $\mathrm{T} 1+2$ distractor modulated the $\mathrm{AB}$, even though it did not affect $\mathrm{T} 1$ performance. These results were replicated in Experiment 3 with a conventional $\mathrm{AB}$ paradigm in which two letter targets were inserted into a stream of digit distractors. This pattern of results is hard to reconcile with either model, but both models can be made to account for the data when appropriately modified.

\section{Experiment 1}

The present work was part of a series of experiments involving event-related potentials (ERPs) in which the frequency of the T2 letter was manipulated in order to compute the frequency-related P3 difference wave. In Experiment 1, both the $\mathrm{T} 1$ and the $\mathrm{T} 2$ stimuli were chosen so as to be compatible with the ERP experiments. The targets were uppercase letters inserted in an RSVP stream of digit distractors. The T1 letter was A, C, D, or E. The T2 letter could be Y (on $25 \%$ of the trials) or $\mathrm{H}$, J, K, L, M, N, P, R, S, T, U, or V (on $75 \%$ of the trials). Participants identified $\mathrm{T} 1$ and indicated whether or not $\mathrm{T} 2$ was a $\mathrm{Y}$.
Method

\section{Participants}

Forty-four undergraduate students at Simon Fraser University participated for course credits or financial compensation. All reported normal or corrected-to-normal vision and were naive as to the purpose of the experiment. Three participants were excluded for not complying with instructions, leaving 41 participants in the final sample.

\section{Apparatus and stimuli}

The experiment was programmed in E-Prime 2.0 and was run on a Pentium PC computer, with a $17-i n$. VGA monitor. The RSVP stream, presented in the center of the screen, consisted of digit distractors (2-9) and two uppercase letter targets, presented in 20-point bold Courier New font. All the stimuli were white and were presented on a darker gray background. T1 was chosen randomly from the letters A, C, $\mathrm{D}$, and $\mathrm{E} . \mathrm{T} 2$ was chosen from the letters $\mathrm{H}, \mathrm{J}, \mathrm{K}, \mathrm{L}, \mathrm{M}, \mathrm{N}$, $\mathrm{P}, \mathrm{R}, \mathrm{S}, \mathrm{T}, \mathrm{U}, \mathrm{V}$, and $\mathrm{Y}$. The letter $\mathrm{Y}$ was presented on $25 \%$ of the trials (infrequent T2 response category), and one of the other letters was presented randomly on the other $75 \%$ of the trials (frequent T2 response category). Infrequent and frequent $\mathrm{T} 2$ response category trials were presented randomly in each block.

Each item in the RSVP stream remained on the screen for $50 \mathrm{~ms}$ and was separated from the next item by an interstimulus interval (ISI) of $50 \mathrm{~ms}$, yielding a presentation rate of 10 items/s. The number of distractors preceding $\mathrm{T} 1$ was determined randomly on each trial and varied between 18 and 24. On any given trial, the distractors were selected randomly, with replacement, from the set of digits 2-9, with the constraint that the selected digit was not one of the two preceding items. T2 was then presented either at lag 3 (short lag) or at lag 9 (long lag). In the no-distractor condition, the two digits following T1 (i.e., in the lag 1 and lag 2 positions) were replaced by 50-ms blank frames. In the $\mathrm{T} 1+1$ condition, the digit in the lag 2 position was replaced by a 50 -ms blank frame, and in the $\mathrm{T} 1+2$ condition, the digit in the lag 1 position was replaced by a 50-ms blank frame. On short-lag trials, T2 was presented at lag 3 and was followed by a one-digit distractor that acted as a mask. On long-lag trials, digits continued to be presented from lag 3 to lag 8 , and then $\mathrm{T} 2$ was presented, followed by a digit mask. Figure 1 illustrates the RSVP stream for the short lag in all three conditions.

\section{Design and procedure}

A within-subjects design was employed with three factors: $\mathrm{T} 1$ distractor position (no distractor, $\mathrm{T} 1+1$, or $\mathrm{T} 1+2$ ), 
T1-T2 lag (lag 3 or lag 9), and T2 response category frequency (T2 frequent or T2 infrequent). Each participant took part in one session, consisting of two blocks of 240 trials preceded by one practice block of 24 trials. All conditions were intermixed randomly in each block of trials.

At the beginning of the session, participants were required to read the instructions displayed on the screen and were invited to ask questions to clarify procedural details. Participants were instructed to ignore the distractors and to report, without speeded pressure, the identity of $\mathrm{T} 1$ by pressing the $\mathrm{Z}, \mathrm{X}, \mathrm{C}$, or V key on the keyboard with the left hand for $\mathrm{A}, \mathrm{C}, \mathrm{D}$, and $\mathrm{E}$ responses, respectively, and to report whether $\mathrm{T} 2$ was a $\mathrm{Y}$ or not by pressing the $\mathrm{N}$ or $\mathrm{M}$ key with the right hand for $\mathrm{Y}$ and not- $\mathrm{Y}$ responses, respectively.

At the beginning of each trial, a small fixation cross was presented in the center of the screen, indicating the location at which the RSVP stream was about to appear. Participants initiated each trial by pressing the space bar. The RSVP stream started 200-500 ms after trial initiation. Eight hundred ms after the stream ended, a first question-"First letter: A, C, D, or E?"—was displayed until response. A second question-"Second letter: Y or not Y?"-was displayed, immediately after the first response, until the second response was executed, at which point the fixation cross reappeared, indicating readiness for the next trial. The instructions emphasized the importance of responding " $Y$ " only when a $\mathrm{Y}$ was seen.

\section{Results}

T1 performance was about the same in the two T2frequency conditions (no main effect or interactions with this factor; see below). For this reason, the T1 scores were combined over frequent and infrequent T2 trials. Analyses of T2 performance were performed only for T2-infrequent trials on which $\mathrm{T} 1$ was reported correctly. T2-frequent trials were excluded from the analyses because participants were instructed to make a "Y" response only if a $\mathrm{Y}$ was seen. Therefore, if participants did not consciously "see" the second letter, they would answer "not- $Y$ ". This renders the frequent- $\mathrm{T} 2$ trials uninformative with respect to the $\mathrm{AB}$, because a "not- $Y$ " response could indicate either that a letter other than $\mathrm{Y}$ had been displayed or that the letter $\mathrm{Y}$ had been displayed but had been missed because an AB had occurred. Accuracy of T2 identification on T2-frequent trials was very high ( $94 \%$ or higher in all conditions), indicating that participants were following instructions.

\section{T1 Performance}

The percentages of correct identifications of $\mathrm{T} 1$, averaged over participants, are shown in Table 1 . The data were analyzed in a repeated measures analysis of variance (ANOVA) with two within-subjects factors: lag (two levels: lag 3 and lag 9) and T1 distractor (three levels: no distractor, $\mathrm{T} 1+1$, and $\mathrm{T} 1+2$ ). The analysis revealed only a main effect of T1 distractor, $F(2,80)=50.39, M S E=14.35$, $p<.001$. No other effects were significant (all $F_{S}<1$ ). Pairwise comparisons confirmed that T1 accuracy was lower in the $\mathrm{T} 1+1$ condition $(88.9 \%)$ than in the nodistractor $(94.5 \% ; t(40)=8.21, p<.001)$ or in the $\mathrm{T} 1+2$ condition $(93.3 \% ; t(40)=6.64, p<.001)$. The $\mathrm{T} 1+2$ and the no-distractor conditions did not differ significantly at lag 3 , $t(40)=1.68, p>.05$, but performance in the no-distractor condition was more accurate by $1.2 \%$ at $\operatorname{lag} 9, t(40)=2.19$, $p=.04$. When frequent trials were excluded from the analysis, the pattern of results was unchanged, except that the $\mathrm{T} 1+2$ and the no-distractor conditions did not differ significantly either at lag $3, t(40)=.45, p>.05$, or at lag 9 , $t(40)=1.83, p>.05$.

\section{T2 performance}

For reasons noted above, only the data for the T2infrequent condition were used in the analysis of $\mathrm{T} 2$ performance. The result of principal interest was the magnitude of the $\mathrm{AB}$ obtained in the three conditions (no distractor, $\mathrm{T} 1+1$, and $\mathrm{T} 1+2$; see the "Theoretical Considerations" section in the introduction). Accordingly, we computed the magnitude of the $\mathrm{AB}$ by subtracting each participant's percentage of correct $\mathrm{T} 2 \mid \mathrm{T} 1$ responses at lag 3 from the corresponding score at lag 9 , separately for each of the three conditions. Those scores, averaged over participants, are illustrated in Fig. 2. The percentages of
Table 1 Mean percentage of correct $\mathrm{T} 1$ responses for each lag in the no distractor (ND), $\mathrm{T} 1+1$, and $\mathrm{T} 1+2$ conditions in each of the three experiments

\begin{tabular}{|c|c|c|c|c|c|c|c|c|}
\hline \multirow[t]{3}{*}{ Condition } & \multicolumn{4}{|l|}{ Exp. 1} & \multirow{2}{*}{\multicolumn{2}{|c|}{ Exp. 2}} & \multirow{2}{*}{\multicolumn{2}{|c|}{ Exp. 3}} \\
\hline & \multicolumn{2}{|c|}{ T2 Frequent } & \multicolumn{2}{|c|}{ T2 Infrequent } & & & & \\
\hline & Lag 3 & Lag 9 & Lag 3 & Lag 9 & Lag 3 & Lag 9 & Lag 3 & Lag 9 \\
\hline ND & 95 & 94 & 95 & 95 & 90 & 89 & 94 & 93 \\
\hline $\mathrm{T} 1+1$ & 88 & 88 & 89 & 90 & 84 & 86 & 88 & 86 \\
\hline $\mathrm{T} 1+2$ & 93 & 93 & 94 & 93 & 89 & 89 & 93 & 92 \\
\hline
\end{tabular}


Fig. 2 Magnitude of the condition in Experiment 1. Two separate unspeeded responses were required on each trial. The first response was a four-alternative discrimination to the first letter (T1), chosen The second response was a two-alternative discrimination as to whether the second letter (T2) was a Y $(25 \%$ of the trials $)$ or not $(75 \%$ of the trials) attentional blink for each randomly from $\mathrm{A}, \mathrm{C}, \mathrm{D}$, or $\mathrm{E}$.

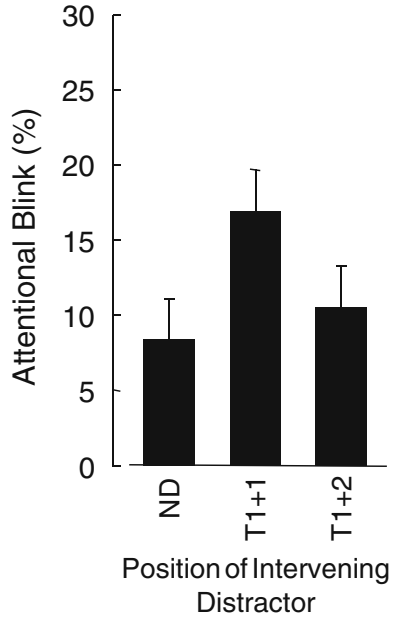

correct identifications of $\mathrm{T} 2 \mid \mathrm{T} 1$, averaged over participants, are shown in Table 2. Perhaps the most notable aspect of the results in Fig. 2 is that an $\mathrm{AB}$ was obtained even when no distractors intervened between the two targets (no distractor condition), indicating that the presence of intervening distractors is not necessary to produce an $\mathrm{AB}$.

The pattern of results in Fig. 2 mimics the pattern observed for $\mathrm{T} 1$ accuracy (Table 1) and suggests that an intervening distractor can modulate the $\mathrm{AB}$ only indirectly, via its effect on $\mathrm{T} 1$ processing. This is in line with capacitybased models, which propose that the magnitude of the $\mathrm{AB}$ should be related inversely to the accuracy of $\mathrm{T} 1$ identification. These observations were supported by the outcome of a within-subjects one-way ANOVA with position of the $\mathrm{T} 1$ distractor at three levels: no distractor, $\mathrm{T} 1+1$, and $\mathrm{T} 1+2$. The analysis revealed a significant effect of T1 distractor, $F(2,80)=4.42, M S E=171.80, p=.015$. A one-sample $t$ test confirmed that an $\mathrm{AB}$ was obtained in the no-distractor condition, $t(40)=2.94, p=.005$. Planned pairwise comparisons confirmed that the $\mathrm{AB}$ in the $\mathrm{T} 1+1$ condition was significantly larger than that in either the nodistractor condition, $t(40)=2.59, p=.013$, or the $\mathrm{T} 1+2$ condition, $t(40)=2.34, p=.024$, which did not differ significantly from one another, $t(40)=0.74, p>.05$.

Table 2 Mean percentage of correct T2|T1 responses for each lag in the No Distractor (ND), T1 +1 , and $\mathrm{T} 1+2$ conditions in each experiment

\begin{tabular}{|c|c|c|c|c|c|c|}
\hline \multirow[t]{2}{*}{ Condition } & \multicolumn{2}{|l|}{ Exp. 1} & \multicolumn{2}{|l|}{ Exp. 2} & \multicolumn{2}{|l|}{ Exp. 3} \\
\hline & Lag 3 & Lag 9 & Lag 3 & Lag 9 & Lag 3 & Lag 9 \\
\hline ND & 83 & 92 & 79 & 86 & 83 & 94 \\
\hline $\mathrm{T} 1+1$ & 74 & 91 & 70 & 84 & 64 & 91 \\
\hline $\mathrm{T} 1+2$ & 83 & 94 & 74 & 86 & 73 & 93 \\
\hline
\end{tabular}

\section{Discussion}

In the present experiment, we used two intertarget lags (lags 3 and 9) and presented an intervening distractor at lag $1(\mathrm{~T} 1+1$ condition) at lag 2 (T1 +2 condition), or at neither lag (nodistractor condition). Our objective was to determine whether intervening distractors are necessary to produce an $\mathrm{AB}$ and, if so, whether distractors modulate the $\mathrm{AB}$ directly, as is proposed in distractor-based theories, or indirectly by affecting $\mathrm{T} 1$ processing, as is proposed in capacity-based theories. ${ }^{1}$

As was expected, accuracy for $\mathrm{T} 1$ was lowest in the $\mathrm{T} 1+1$ condition, in which the distractor/mask was presented directly after T1. Importantly, an AB was observed in all the distractor conditions, including the no-distractor condition, in which, at lag 3, T1 and T2 were separated by an uninterrupted blank interval (see Nieuwenstein, Potter, \& Theeuwes, 2009, for a similar finding). The fact that an $\mathrm{AB}$ was observed in the nodistractor condition clearly demonstrates that intervening distractors are not critical for the $\mathrm{AB}$, a finding that is contrary to the fundamental assumption made in distractor-

\footnotetext{
${ }^{1}$ Several aspects of our design were similar to the design used by Raymond et al. (1992, Experiment 3 and 4). Specifically, Raymond et al. presented a white letter (T1) among black letters, which could be followed at varying SOAs by an X (T2, present on $50 \%$ of the trials). The participants' task was to report the identity of T1 and whether T2 was present or absent. Importantly, a blank frame was presented directly after $\mathrm{T} 1$ (Experiment 3 ) or $90 \mathrm{~ms}$ after T1, with a distractor intervening between $\mathrm{T} 1$ and the blank frame (Experiment 4). The duration of the blank frame was $0 \mathrm{~ms}$ (no blank), $90 \mathrm{~ms}$ (one frame), $180 \mathrm{~ms}$ (two frames), or $270 \mathrm{~ms}$ (three frames). If we consider the trials on whichT2 was presented $270 \mathrm{~ms}$ after the onset of T1 (i.e., at lag 3), the 90- and 180-ms blank conditions in Experiment 3 are equivalent to our short-lag $\mathrm{T} 1+2$ and no-distractor conditions, respectively, and the $90-\mathrm{ms}$ blank condition in Experiment 4 is equivalent to our short lag $\mathrm{T} 1+1$ condition.

Comparisons among the three conditions at lag 3 in Raymond et al. (1992) study, however, is not entirely straightforward. For example, there was a difference in T2 accuracy of approximately $20 \%$ in the 0 ms blank condition between Experiments 3 and 4, even though this condition was identical in the two experiments. This betweenexperiment comparison can be avoided by confining the comparisons to just Experiment 3. It might be argued that the 0 -ms blank condition in Experiment 3 could approximate our $\mathrm{T} 1+1$ condition, although a distractor was presented in the $\mathrm{T} 1+2$ position in their study, but not in ours. This argument would be based on the assumption that the first distractor presented after $\mathrm{T} 1$ should be the only source of impairment on both $\mathrm{T} 1$ and $\mathrm{T} 2$ performance. This assumption could be justified by the finding that in Experiment 4 in Raymond et al. (Figure 6), T2 accuracy at lag 3 was about the same in the 0-ms (two intervening distractors between T1 and T2) and the 90-ms blank (a distractor followed by a blank between the two targets) conditions. Pursuing this argument, although it seems clear from Figure 5 in Raymond et al. that T2 accuracy at lag 3 was lower in the 0 -ms blank condition than in either the $90-\mathrm{ms}$ or the 180 -ms blank condition, it is less clear whether T2 accuracy differed between the two last conditions. Given the absence of any statistical analysis at lag 3, for either T1 or T2, it was important to replicate these conditions here, using a similar design, and to perform an appropriate statistical test in respect to the question at hand.
} 
based models (Di Lollo et al., 2005; Olivers \& Meeters, 2008; Taatgen, Juvina, Schipper, \& Martens, 2009).

Furthermore, the finding that the $\mathrm{AB}$ was of approximately equal magnitude in the no-distractor and $\mathrm{T} 1+2$ conditions strongly suggests that intervening distractors not only are unnecessary for the $\mathrm{AB}$, but also can affect the $\mathrm{AB}$ only indirectly by increasing $\mathrm{T} 1$ difficulty. Had distractors interfered directly with $\mathrm{T} 2$ identification, we should have seen a larger $\mathrm{AB}$ when an intervening distractor was presented (the $\mathrm{T} 1+2$ condition) than when no intervening distractor was presented. This should be the case even in the absence of any effect of the distractor on T1 accuracy.

Although the results of Experiment 1 seem to provide compelling evidence against the proposition that intervening distractors produce or modulate the $\mathrm{AB}$ directly, it is possible that the outcome might have been influenced by a task switch that occurred between $\mathrm{T} 1$ and $\mathrm{T} 2$. The presence of a task switch is known to modulate the AB (e.g., Juola, Botella, \& Palacios, 2004; Kawahara, Zuvic, Enns, \& Di Lollo, 2003; Potter, Chun, Banks, \& Muckenhoupt, 1998; Vachon, Tremblay, \& Jones, 2007; Visser, Bischof, \& Di Lollo, 1999). To be sure, in the present experiment, both $T 1$ and $T 2$ were letters, but the specific tasks associated with the two targets were different. The $\mathrm{T} 1$ task was to identify the target in a four-alternative forced choice among the letters A, C, D, and $\mathrm{E}$. The T2 task, on the other hand, was to detect whether T2 - chosen from the letters $\mathrm{H}, \mathrm{J}, \mathrm{K}, \mathrm{L}, \mathrm{M}, \mathrm{N}, \mathrm{P}, \mathrm{R}, \mathrm{S}, \mathrm{T}, \mathrm{U}$, $\mathrm{V}$, and $\mathrm{Y}$-was or was not a $\mathrm{Y}$. It is therefore possible that an online reconfiguration of the attentional filter (from an "A, C, D, E" filter to a "Y" filter) and, possibly, a reconfiguration of the stimulus-response mapping might have occurred in Experiment 1. It is worth noting, at least in passing, that a similar task switch may have been present in Raymond et al. (1992) study, because the attentional filter for T1 ("white" filter) was different from the filter for T2 ("X" filter).

It is of interest to note that an $\mathrm{AB}$ triggered by task switching can be encompassed within the TLC model in which the $\mathrm{AB}$ is the result of a disruption of the attentional filter, set to select targets with maximal efficiency. If $\mathrm{T} 1$ and $\mathrm{T} 2$ require different filters, the filter set to select $\mathrm{T} 1$ at the beginning of the trial would have to be reconfigured upon detection of $\mathrm{T} 1$, in order to maximize selection efficiency for T2. Given that reconfiguration cannot take place during the $\mathrm{AB}$, there may not be sufficient time to reconfigure the filter when $\mathrm{T} 2$ is presented at lag 3 . This could lead to an AB-like effect even in the no-distractor condition.

\section{Experiment 2}

A task switch between $\mathrm{T} 1$ and $\mathrm{T} 2$ was eliminated in Experiment 2 by making the T2 task the same as the T1 task. In both cases, participants were required to indicate whether the target was A, C, D, or E. The four letters were presented randomly as $\mathrm{T} 1$ and $\mathrm{T} 2$. However, to avoid repetition blindness effects (Kanwisher, 1987), all trials on which $\mathrm{T} 1$ and $\mathrm{T} 2$ shared the same identity were removed from the analyses. To the extent that task switching produced an $\mathrm{AB}$ in the no-distractor condition in Experiment 1 , elimination of the task switch should result in a corresponding elimination of the $\mathrm{AB}$ in Experiment 2.

Method

\section{Participants}

Forty-eight undergraduate students at Simon Fraser University participated in this experiment for course credit or financial compensation. All reported normal or corrected-to-normal vision and were naive as to the purpose of the experiment.

\section{Apparatus and stimuli}

The apparatus and stimuli were the same as those in Experiment 1, with the exception that $\mathrm{T} 2$ was chosen from the same set of four letters (A, C, D, and E) as T1.

\section{Design and procedure}

A within-subjects design was employed with two factors: T1 distractor (no distractor, $\mathrm{T} 1+1$, or $\mathrm{T} 1+2$ ), and $\mathrm{T} 1-\mathrm{T} 2$ lag (lag 3 or lag 9). Each participant took part in one experimental session, consisting of two blocks of 192 trials preceded by one practice block of 24 trials. All conditions were randomly intermixed in each block of trials. All 16 combinations of T1 and $\mathrm{T} 2$ letters were presented equally often in each block. Therefore, $\mathrm{T} 1$ and $\mathrm{T} 2$ had a different identity on $75 \%$ of the trials and were the same on the other $25 \%$ of the trials.

The procedure was the same as that in Experiment 1, except that participants were required to report the identity of T2 by pressing the N, M, [,], or [.] key with the right hand for $\mathrm{A}, \mathrm{C}, \mathrm{D}$, and $\mathrm{E}$ in response to the screen prompt "Second letter: A, C, D, or E?"

\section{Results}

To avoid confounding with repetition blindness effects, trials on which $\mathrm{T} 1$ and $\mathrm{T} 2$ had the same identity were excluded from the analyses. Order of report was ignored when scoring the responses.

\section{T1 performance}

The percentages of correct identifications of T1, averaged over participants, are shown in Table 1. As was the case in 
Experiment 1, T1 accuracy was lowest in the $\mathrm{T} 1+1$ condition, in which $\mathrm{T} 1$ was masked by the immediately following distractor, and was equivalent in the other two conditions. The data were analyzed in a repeated measures ANOVA with two within-subjects factors: lag (two levels: lag 3 and lag 9) and T1 distractor (three levels: no distractor, $\mathrm{T} 1+1$, and $\mathrm{T} 1+2)$. The analysis yielded a significant effect of T1 distractor, $F(2,94)=33.99, \mathrm{MSE}=19.04, p<.001$, but neither the effect of lag $(F<1)$ nor the lag $\times \mathrm{T} 1$ distractor interaction, $F(2,94)=3.03$, MSE $=11.81, p>.05$, reached significance. As in Experiment 1, planned pairwise comparisons confirmed that $\mathrm{T} 1$ accuracy was lower in the $\mathrm{T} 1+1$ condition $(84.8 \%)$ than in either the no-distractor condition $(89.5 \%), t(47)=6.67, p<.001$, or the $\mathrm{T} 1+2$ condition $(89.1 \%), t(47)=6.16, p<.001$, which did not differ significantly from one another, $t(47)=0.83, p>.05$.

\section{T2 performance}

The magnitude of the $\mathrm{AB}$ was calculated as in Experiment 1. The AB scores, averaged over participants, are illustrated in Fig. 3. The percentages of correct identifications of $\mathrm{T} 2 \mid \mathrm{T} 1$, averaged over participants, are shown in Table 2, separately for each condition and lag.

As was the case in Experiment 1, an $\mathrm{AB}$ was obtained in all three conditions. Unlike in Experiment 1, however, the $\mathrm{AB}$ in the $\mathrm{T} 1+2$ condition was larger than that in the nodistractor condition, even though $\mathrm{T} 1$ accuracy was not affected by the $\mathrm{T} 1+2$ distractor. This means that intervening distractors can modulate the $\mathrm{AB}$ directly in the absence of a task switch. Notably, intervening distractors can modulate the magnitude of the $A B$ even though they are not necessary for producing the $\mathrm{AB}$ itself, as evidenced by the $\mathrm{AB}$ obtained in the no-distractor condition (Fig. 3).

These observations were supported by the outcome of a within-subjects one-way ANOVA with position of the T1 distractor at three levels: no distractor, $\mathrm{T} 1+1$, and $\mathrm{T} 1+2$. The analysis revealed a significant effect of $\mathrm{T} 1$ distractor,

Fig. 3 Magnitude of the attentional blink for each condition in Experiment 2

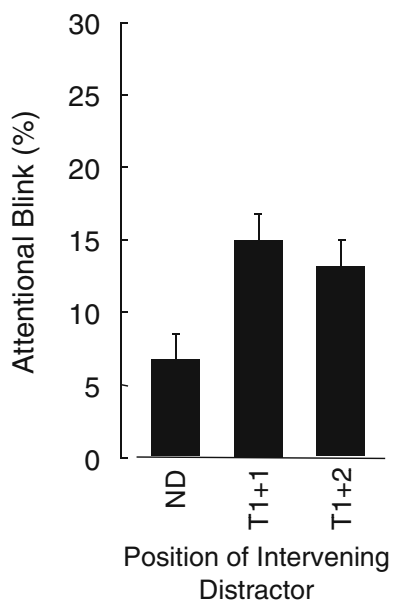

$F(2,94)=8.94, M S E=84.05, p<.001$. A one-sample $t$ test confirmed that an $\mathrm{AB}$ was obtained in the no-distractor condition, $t(47)=4.30, p<.001$. Planned pairwise comparisons confirmed that the $\mathrm{AB}$ in the $\mathrm{T} 1+1$ condition was significantly larger than that in the no-distractor condition, $t(47)=3.74, p<.001$, but did not differ from that in the $\mathrm{T} 1+2$ condition, $t(47)=1.12, p>.05$. The $\mathrm{AB}$ was significantly larger in the $\mathrm{T} 1+2$ condition than in the no-distractor condition, $t(47)=2.97, p=.005$.

The principal objective of Experiment 2 was to find out whether the ABs obtained in Experiment 1 were due, at least in part, to a task switch between $\mathrm{T} 1$ and $\mathrm{T} 2$. A direct comparison of the two experiments revealed no evidence of task switching on the magnitude of the $\mathrm{AB}$. The results of the two experiments were compared directly in an ANOVA with one between-subjects factor at two levels (experiment: 1 and 2) and one within-subjects factor at three levels (condition: no distractor, $\mathrm{T} 1+1$, and $\mathrm{T} 1+2$ ). The analysis revealed a significant effect of condition, $F(2,174)=11.17$, MSE $=124.40, p<.001$. Neither the effect of experiment nor the interaction effect reached significance (both $F_{\mathrm{S}}<1$ ). Planned pairwise comparisons confirmed that a larger $\mathrm{AB}$ was obtained in the $\mathrm{T} 1+2$ condition $(11.7 \%)$ than in the no-distractor condition $(7.6 \%), t(88)=2.43, p=.017$.

\section{Discussion}

Two aspects of the results of Experiment 2 are especially relevant. First, a significant $\mathrm{AB}$ was obtained in the nodistractor condition. Notably, the absence of an interaction effect in the combined analysis of Experiments 1 and 2 indicates that the magnitude of the $\mathrm{AB}$ obtained in the nodistractor condition in Experiment 2 was comparable to that obtained in the corresponding condition in Experiment 1. This finding strongly suggests that task switching was not selectively responsible for the ABs obtained in Experiment 1. By the same token, the presence of an $\mathrm{AB}$ in the no-distractor condition in both experiments confirms that distractors are not necessary to produce an $\mathrm{AB}$. This outcome is clearly consistent with predictions from capacity-based theories, but not from distractor-based theories.

Second, the results of the combined analysis show that a larger $\mathrm{AB}$ was obtained in the $\mathrm{T} 1+2$ condition than in the no-distractor condition. The absence of a corresponding difference in $\mathrm{T} 1$ performance (see above) is consistent with the hypothesis that the intervening distractor in the $\mathrm{T} 1+2$ condition mediated the $\mathrm{AB}$ directly, rather than indirectly, through masking of T1. As is shown in Table 1, T1 performance never exceeded $90 \%$, suggesting that the equivalent performance in the $\mathrm{T} 1+2$ and the nodistractor conditions was not the result of a ceiling effect. This pattern of results is consistent with distractor-based 
theories, but not with capacity-based theories, which predict that intervening distractors modulate the $\mathrm{AB}$ only indirectly by masking $\mathrm{T} 1$.

\section{Experiment 3}

The larger $\mathrm{AB}$ in the $\mathrm{T} 1+2$ condition, relative to the nodistractor condition, in Experiment 2 was interpreted as favoring distractor-based models. That interpretation, however, depended critically on the null finding that accuracy of $\mathrm{T} 1$ identification was approximately the same in those two conditions. Although the sample size in Experiment 2 was large $(N=48)$ and the null effect was likely not due to a ceiling effect, we thought it prudent to replicate those findings. This was done in Experiment 3, using a conventional $\mathrm{AB}$ paradigm in which the two targets were chosen from a larger pool of letters (all the letters in the English alphabet, excepting B, O, Q, Y, and Z).

A second objective of Experiment 3 was to examine the hypothesis that the impairment in $\mathrm{T} 2$ identification in the $\mathrm{T} 1+$ 2 condition, relative to the no-distractor condition, in Experiment 2 might have arisen from forward masking. It is possible that identification of $\mathrm{T} 2$ in the $\mathrm{T} 1+2$ condition was impaired not only because the target was presented during the period of the $\mathrm{AB}$, but also because it was forward-masked by the distractor presented immediately ahead of it. No such masking could have occurred in the no-distractor condition, because $\mathrm{T} 2$ was preceded by a blank screen. We checked on this forward-masking option by omitting the distractor immediately preceding $\mathrm{T} 2$ at lag 9 on half of the trials. Showing that this manipulation has no effect on T2 identification would provide evidence that forward masking was not an important determinant of the AB in Experiment 2.

\section{Method}

\section{Participants}

Thirty-four undergraduate students at Simon Fraser University participated in this experiment for course credit or financial compensation. All reported normal or correctedto-normal vision and were naive as to the purpose of the experiment.

\section{Apparatus and stimuli}

The apparatus and stimuli were the same as those in Experiments 1 and 2, with two exceptions. First, T1 and T2 were uppercase letters chosen randomly from the English alphabet, excepting $\mathrm{B}, \mathrm{O}, \mathrm{Q}, \mathrm{Y}$, and $\mathrm{Z}$. Second, the distractor immediately preceding $\mathrm{T} 2$ was replaced randomly by a blank on half of the trials at lag 9 .

\section{Design and procedure}

The design and procedure were the same as those in Experiment 2, except that participants reported the identity of each target by pressing the corresponding key on the keyboard when prompted.

\section{Results and discussion}

As in Experiment 2, trials on which $\mathrm{T} 1$ and $\mathrm{T} 2$ had the same identity were excluded from the analyses. Order of report was ignored when scoring the responses.

The forward-masking hypothesis outlined above was not supported by the experimental outcome. Accuracy of T2 identification at lag 9 was approximately the same when $\mathrm{T} 2$ was preceded by a distractor/forward-mask $(91.1 \%)$ as when it was preceded by a blank screen $(91.4 \%), t(33)=$ $0.42 ; p>.05$, This outcome strongly suggests that the larger $\mathrm{AB}$ in the $\mathrm{T} 1+2$ condition than in the no-distractor condition in Experiment 2 was unlikely to have been caused by forward masking of T2 by the immediately preceding distractor in the $\mathrm{T} 1+2$ condition.

\section{T1 performance}

The percentages of correct identifications of $\mathrm{T} 1$, averaged over participants, are shown in Table 1. As was the case in Experiments 1 and 2, T1 accuracy was lowest in the $\mathrm{T} 1+1$ condition, in which $\mathrm{T} 1$ was masked by the immediately following distractor, and was equivalent in the other two conditions. The data were analyzed in a repeated measures ANOVA with two within-subjects factors: lag (two levels: lag 3 and lag 9) and T1 distractor (three levels: no distractor, $\mathrm{T} 1+1$, and $\mathrm{T} 1+2$ ). The analysis yielded a significant effect of $\mathrm{T} 1$ distractor, $F(2,66)=36.71, \mathrm{MSE}=20.97, \mathrm{p}<.001$, but neither the effect of lag, $F(1,33)=3.08, \mathrm{MSE}=24.50, \mathrm{p}>.05$, nor the lag $\times \mathrm{T} 1$ distractor interaction, $F<1$, reached significance. As in Experiments 1 and 2, planned pairwise comparisons confirmed that $\mathrm{T} 1$ accuracy was lower in the $\mathrm{T} 1+1$ condition $(87.0 \%)$ than in the no-distractor condition (93.2\%), $t(34)=6.50 p<.001$, or in the $\mathrm{T} 1+$ 2 condition $(92.3 \%), t(34)=4.82, p<.001$, which did not differ significantly from one another, $t(34)=1.86, p>.05$.

One of the principal findings in the present study was that, contrary to expectations from capacity-based theories, a larger $\mathrm{AB}$ was obtained in the $\mathrm{T} 1+2$ condition than in the nodistractor condition, without a corresponding difference in $\mathrm{T} 1$ performance. To confirm the robustness of the latter outcome, we combined the T1 data for Experiments 2 and 3 in a single ANOVA with one within-subjects factor (condition: $\mathrm{T} 1+2$ and no distractor) and one between-subjects factor (experi- 
ment: 2 and 3). Even though the sample size was increased to $N=82$, there was still no sign of a significant difference in $\mathrm{T} 1$ performance between the no-distractor condition $(91.6 \%)$ and the $\mathrm{T} 1+2$ condition $(91.1 \%), F<1$.

\section{T2 performance}

The magnitude of the $\mathrm{AB}$ was calculated as in Experiments 1 and 2. The $\mathrm{AB}$ scores, averaged over participants, are illustrated in Fig. 4. The percentages of correct identifications of $\mathrm{T} 2 \mid \mathrm{T} 1$, averaged over participants, are shown in Table 2, separately for each condition and lag.

The overall pattern of results was similar to that in Experiment 2 (Fig. 3). Notably, a substantial AB was obtained in the no-distractor condition, consistent with capacity-based, but not with distractor-based, theories. On the other hand, a larger AB was again obtained in the $\mathrm{T} 1+$ 2 condition than in the no-distractor condition in the absence of a corresponding difference in $\mathrm{T} 1$ performance, consistent with distractor-based, but not with capacitybased, theories.

These observations were supported by the outcome of a within-subjects one-way ANOVA with position of the T1 distractor at three levels: no distractor, $\mathrm{T} 1+1$, and $\mathrm{T} 1+2$. The analysis revealed a significant effect of $\mathrm{T} 1$ distractor, $F(2,64)=19.09, \mathrm{MSE}=98.86, p<.001$. A one-sample $t$ test confirmed that an $\mathrm{AB}$ was obtained in the nodistractor condition, $t(32)=6.17, p<.001$. Planned pairwise comparisons confirmed that the $\mathrm{AB}$ in the $\mathrm{T} 1+1$ condition was significantly larger than those in both the no-distractor condition, $t(33)=5.70, p<.001$, and the $\mathrm{T} 1+2$ condition, $t(33)=2.84, p=.008$. As in Experiment 2, there was also a significantly larger $\mathrm{AB}$ in the $\mathrm{T} 1+2$ condition than in the no-distractor condition, $t(32)=3.55, p=.001$.

In summary, the results of Experiment 3 confirmed that forward masking was not an important factor in the $\mathrm{AB}$

Fig. 4 Magnitude of the attentional blink for each condition in Experiment 3

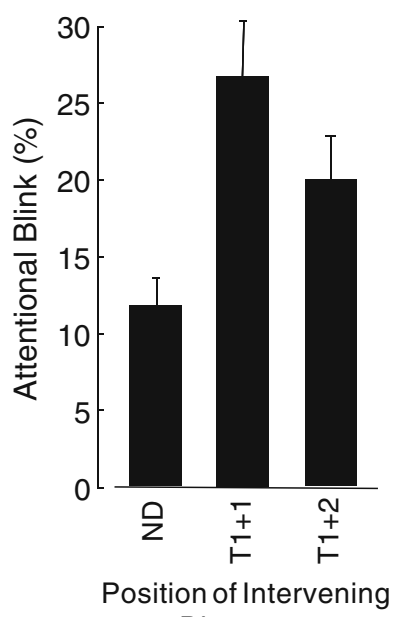

Distractor obtained in Experiment 2. They also added to the robustness of the theoretically important null finding that accuracy of $\mathrm{T} 1$ identification was approximately equal in the $\mathrm{T} 1+2$ and the no-distractor conditions.

\section{General discussion}

The goal of the present study was to determine whether distractors presented during the period of the $\mathrm{AB}$ modulate the magnitude of the $\mathrm{AB}$ directly, as is postulated in distractor-based theories (e.g., Di Lollo et al., 2005; Olivers \& Meeters, 2008; Taatgen et al., 2009), or affect $\mathrm{T} 2$ performance only indirectly via their effect on T1 difficulty, as is postulated in capacity-based theories (Chun \& Potter, 1995; Jolicoeur, 1998, Nieuwenstein \& Potter, 2006; Nieuwenstein et al., 2009; see also Wyble, Bowman, \& Nieuwenstein, 2009). To this end, we manipulated the presence/absence and temporal position of an intervening distractor that was presented at lag 1 , at lag 2, or at neither of these two lags. T2 was presented either at lag 3 or at lag 9. The magnitude of the $A B$ was calculated by subtracting the $\mathrm{T} 2$ score at lag 3 from the corresponding score at lag 9 .

Experiment 1 showed that, consistent with the findings of Nieuwenstein et al. (2009), an AB was obtained in the no-distractor condition, in which the two distractors between $\mathrm{T} 1$ and $\mathrm{T} 2$ were replaced by blanks. This finding is consistent with capacity-based, but not with distractorbased, theories. On the other hand, the finding that a larger $\mathrm{AB}$ occurred in the $\mathrm{T} 1+2$ condition than in the nodistractor condition in the absence of a corresponding difference in $\mathrm{T} 1$ performance is consistent with distractorbased, but not with capacity-based, theories. Experiment 2 showed that the $\mathrm{ABs}$ obtained in Experiment 1 were not due to task switching. Experiment 3 confirmed the theoretically important finding that accuracy of $\mathrm{T} 1$ identification was approximately the same in the $\mathrm{T} 1+2$ and nodistractor conditions and ruled out forward masking of $\mathrm{T} 2$ as a determinant of the $\mathrm{AB}$ in the $\mathrm{T} 1+2$ condition.

An important result in all three Experiments was that an $\mathrm{AB}$ occurred even when no distractors were presented between T1 and T2. Nieuwenstein et al. (2009) reported a similar result, but the $\mathrm{AB}$ was observed only in a condition in which the stimulus onset asynchrony (SOA) between $\mathrm{T} 2$ and its mask was very short $(58 \mathrm{~ms})$. Moreover, the T2 mask was not chosen from the set of digit distractors but was the same unfamiliar pattern mask from trial to trial. Here, we show that the results of Nieuwenstein et al. can be replicated using a typical SOA between $\mathrm{T} 2$ and its mask (100 ms) and when the T2 mask is chosen from the set of distractor digits from the RSVP stream in which the targets were presented. 
Although entirely in line with predictions from capacitybased theories, the finding that an $\mathrm{AB}$ occurs with no distractors intervening between $\mathrm{T} 1$ and $\mathrm{T} 2$ cannot be encompassed within distractor-based theories as presently stated. Predictions from the BB model are disconfirmed because, in that model, the $\mathrm{AB}$ is critically dependent on the bounce response triggered by a post-T1 distractor. Omitting the post-T1 distractors should eliminate the $\mathrm{AB}$, which was clearly not the case in the no-distractor condition. Predictions from the TLC model are similarly disconfirmed, because the disruption of the input filterheld to be the root cause of the AB-depends critically on the presence of post-T1 distractors.

Given a small modification, however, the TLC model can account for the $\mathrm{AB}$ obtained when no distractors intervene between T1 and T2. Namely, it is possible that, in the absence of intervening distractors, the input filter may decay during the period in which the maintenance signals are discontinued while the central processor is busy with T1. On this option, an AB may be observed in the absence of intervening distractors, provided that the intertarget lag is sufficiently long to allow the filter to decay, but not long enough to allow the central processor to resume issuing control signals.

Just as distractor-based models are challenged by the presence of an $\mathrm{AB}$ in the absence of intervening distractors, capacity-based models are challenged by the direct modulation of the $\mathrm{AB}$ by distractors intervening between $\mathrm{T} 1$ and T2. Clearly, these theories need to be revised, or, at least, some of their assumptions need to be made explicit. One plausible option is that an ongoing attentional episode may be disrupted by a post-T1 distractor. Recall that the reengagement model (Nieuwenstein, 2006) and its computational counterpart, the eSTST model (Wyble et al., 2009), assume that attention remains engaged so long as there is target input. Both of these models could account for the direct modulation of the $\mathrm{AB}$ if it is assumed that distracting input presented between $\mathrm{T} 1$ and $\mathrm{T} 2$ (e.g., the $\mathrm{T} 1+2$ distractor) can wipe out any residual trace of $\mathrm{T} 1$ at the input layer, thereby causing an abrupt termination of attentional engagement. ${ }^{2}$

In conclusion, the results of the present work reveal clear limitations in both capacity-based and distractorbased theories of the $\mathrm{AB}$. The finding that intervening distractors can produce an $\mathrm{AB}$ directly without differentially affecting $\mathrm{T} 1$ performance creates a problem for capacity-based theories. The problem can be overcome, however, by the additional assumption that intervening distractors can produce an $\mathrm{AB}$ by disrupting the ongoing attentional episode initiated by T1. Similarly, the presence of an $\mathrm{AB}$ in the absence of intervening distractors

\footnotetext{
${ }^{2}$ We thank Mark Nieuwenstein for pointing this out.
}

creates a problem for distractor-based models. The problem seems intractable for the BB model but can be overcome in the TLC model on the assumption that, in the absence of endogenous control, the attentional filter decays unless maintained exogenously by the onset of subsequent targets or other items that contain taskrelevant features.

Acknowledgments This research was supported by a postdoctoral fellowship from the Fond Québécois de la Recherche en Nature et Technologie awarded to B.B., and by Discovery grants from the Natural Sciences and Engineering Research Council of Canada awarded to T.S. and to V.D.L.

\section{References}

Chun, M. M., \& Potter, M. C. (1995). A two-stage model for multiple target detection in rapid serial visual presentation. Journal of Experimental Psychology: Human Perception and Performance, $21,109-127$.

Di Lollo, V., Kawahara, J., Ghorashi, S. M., \& Enns, J. T. (2005). The attentional blink: Resource depletion or temporary loss of control? Psychological Research, 69, 191-200.

Enns, J. T. (2004). Object substitution and its relation to other forms of visual masking. Vision Research, 44, 1321-1331.

Jolicœur, P. (1998). Modulation of the attentional blink by on-line response selection: Evidence from speeded and unspeeded Task1 decisions. Memory \& Cognition, 26, 1014-1032.

Juola, J. F., Botella, J., \& Palacios, A. (2004). Task- and locationswitching effects on visual attention. Perception \& Psychophysics, 66, 1303-1317.

Kanwisher, N. G. (1987). Repetition blindness: Type recognition without token individuation. Cognition, 27, 117-143.

Kawahara, J., Zuvic, S. M., Enns, J. T., \& Di Lollo, V. (2003). Task switching mediates the attentional blink even without backward masking. Perception \& Psychophysics, 65, 339-351.

Nieuwenstein, M. R. (2006). Top-down controlled, delayed selection in the attentional blink. Journal of Experimental Psychology: Human Perception and Performance, 32, 973-985.

Nieuwenstein, M. R., \& Potter, M. C. (2006). Temporal limits of selection and memory encoding: A comparison of whole versus partial report in rapid serial visual presentation. Psychological Science, 17, 471-475.

Nieuwenstein, M. R., Potter, M. C., \& Theeuwes, J. (2009). Unmasking the attentional blink. Journal of Experimental Psychology: Human Perception and Performance, 35, 159169.

Olivers, C. N. L., \& Meeter, M. (2008). A boost and bounce theory of temporal attention. Psychological Review, 115, 836863.

Olivers, C. N. L., van der Stigchel, S., \& Hulleman, J. (2007). Spreading the sparing: Against a capacity-limited account of the attentional blink. Psychological Research, 71, 126-139.

Potter, M. C., Chun, M. M., Banks, B. S., \& Muckenhoupt, M. (1998). Two attentional deficits in serial target search: The visual attentional blink and an amodal task-switch deficit. Journal of Experimental Psychology: Learning, Memory and Cognition, 24, 979-992.

Raymond, J. E., Shapiro, K. L., \& Arnell, K. M. (1992). Temporary suppression of visual processing in an RSVP task: An attentional blink? Journal of Experimental Psychology: Human Perception and Performance, 18, 849-860. 
Taatgen, N. A., Juvina, I., Schipper, M., Borst, J. P., \& Martens, S. (2009). Too much control can hurt: A threaded cognition model of the attentional blink. Cognitive Psychology, 59, 1-29.

Vachon, F., Tremblay, S., \& Jones, D. M. (2007). Task-set reconfiguration suspends perceptual processing: Evidence from semantic priming during the attentional blink. Journal of Experimental Psychology: Human Perception and Performance, 33, 330-347.
Visser, T. A. W., Bischof, W. F., \& Di Lollo, V. (1999). Attentional switching in spatial and nonspatial domains: Evidence from the attentional blink. Psychological Bulletin, 125, 458-469.

Wyble, B., Bowman, H., \& Nieuwenstein, M. (2009). The attentional blink provides episodic distinctiveness: Sparing at a cost. Journal of Experimental Psychology: Human Perception and Performance, 35, 787-807. 